\title{
Influence of Chemical Composition on Layer Properties of Barrel Steels
}

Zdenek Pokorny, David Dobrocky, Zbynek Studeny

Faculty of Military Technology, University of Defence, Kounicova 156/65, 66210 Brno, Czech Republic. E-mail: zdenek.pokorny@unob.cz, zbynek.studeny@unob.cz

This article deals with influence of chemical composition on depth of diffusion layers and porosity of compound layers after gas nitriding process. Experiments are focused on utilizing of gas nitriding processes for surface treatment. Gas nitriding technologies were applied to steels C 35 (sample A1), 34Cr4 (sample A2) and steel 42CrMo4 (sample A4), which were subsequently evaluated by electron microscopy, GDOES and microhardness methods. The measurements showed the influences of chemical composition of alloying elements in core of material after chemical-heat treatment process on depth of diffusion and influence of technology on development of porosity. Nevertheless, the main task was the description of the porosity development in compound layer after gas nitriding and the increasing of surface hardness and of the depth of diffusion layer according to chemical composition. Gas nitriding process was applied for increasing of surface hardness of material in depth and improving of mechanical properties. Mechanical properties of tested material were significantly increased.

Keywords: gas nitriding; microhardness; nitrided layer; porosity.

\section{Introduction}

Non-equilibrium structure is due to redistribution of alloying elements in crystal lattice more suitable for diffusion process. The aim of this paper is to achieve an enhanced surface hardness and reduced friction coefficient with predictable occurrence of porosity. It is well known that the nitrides of iron are primarily created during the nitriding process. These types of nitrides caused only little increasing of microhardness level. The alloying elements, such as $\mathrm{Cr}$, Mo, ensure faster and higher increasing of mechanical properties. Their impact to the creation of diffusion layer is described in this paper. During gas nitriding process, two different layers are mostly effectively created. Firtsly, a compound layer which is consisted of $\varepsilon-\mathrm{Fe}_{2-3} \mathrm{~N}$ and $\gamma-\mathrm{Fe}_{4} \mathrm{~N}$ phase is usually created on the surface of steel $[1,2]$. Ratio of individual phases is dependent on the carbon concentration in steel [1]. The compound layer has been very hard and brittle with good friction and anticorrosion properties [2]. Secondly, a diffusion layer which are mostly created underneath the compound layer.

After the finish of gas nitriding process a new established compound layer mostly contents pores, for instead the significant occurrence of pores very often exists in the surface and defined depth of compound layers. There are many options which are able to be used to pores. The thickness and hardness of $\gamma^{\prime}-\mathrm{Fe}_{4} \mathrm{~N}$ (diffusion layer) depends on quantity and quality of alloying elements [3-5]. This article describes the influence of selected alloying elements on the thickness of the diffusion layer and on the porosity of the compound layer. The porosity is always presented in the surface layer and be able to have bad influence on mechanical properties and the wear resistance.

Chemical composition of steel was checked up by GDOES/Bulk method on LECO SA 2000 spectrometer and local measurement of composition was carried out on SEM microscope Hitachi Tabletop 3000. Microstructure was evaluated by electron microscopy method on Hitachi Tabletop 3000. Thickness and microhardness of nitrided layers were measured by microhardness method in accordance with DIN 50190 standard on automatic microhardness tester LECO LM 247 AT $[6,7]$.

\section{Materials and methods}

Steel C35 (sample A1), 34Cr4 (sample A2) and $42 \mathrm{CrMo} 4$ (sample A4) in untreated state were heattreated (Tab. 1). The quenching and tempering processes were performed due to obtain two different microstructures with different parameters of initial microhardness and different redistribution of ion in crystal lattice.

Tab. 1 Temperatures of heat-treated steels

\begin{tabular}{|c|c|c|c|}
\hline \multirow{2}{*}{ Steel } & \multirow{2}{*}{ Sample } & \multicolumn{3}{|c|}{ Procedure } \\
\cline { 3 - 4 } & & Quenching/20' & Tempering/30' \\
\hline C35 & A1 & $860^{\circ} \mathrm{C}$, water & $600{ }^{\circ} \mathrm{C}$, air \\
\hline 34Cr4 & A2 & $840{ }^{\circ} \mathrm{C}$, water & $600^{\circ} \mathrm{C}$, water \\
\hline $42 \mathrm{CrMo} 4$ & A4 & $850{ }^{\circ} \mathrm{C}$, oil & $600^{\circ} \mathrm{C}$, water \\
\hline
\end{tabular}

The chemical composition of material was evaluated by GDOES/Bulk method (Tab. 2). Glow discharge optical spectroscopy (GDOES) measurements were performed in LECO SA-2000, with argon glow discharge plasma excitation source, calibration of nitrogen: JK41$1 \mathrm{~N}$ and NSC4A standards.

Tab. 2 Chemical composition of A1, A2 and A4 steel measured by GDOES/BULK method

\begin{tabular}{|c|c|c|c|c|c|c|c|}
\hline & \multicolumn{7}{|c|}{ Concentration [wt. \%] } \\
\hline Sample & $\mathrm{C}$ & $\mathrm{Mn}$ & $\mathrm{Si}$ & $\mathrm{Cr}$ & $\mathrm{Ni}$ & $\mathrm{Mo}$ & $\mathrm{Al}$ \\
\hline $\mathrm{A} 1$ & 0.36 & 0.68 & 0.33 & 0.08 & 0.04 & - & 0.003 \\
\hline $\mathrm{A} 2$ & 0.35 & 0.70 & 0.35 & 1.06 & 0.05 & - & 0.035 \\
\hline $\mathrm{A} 4$ & 0.38 & 0.81 & 0.35 & 1.09 & 0.06 & 0.19 & 0.019 \\
\hline
\end{tabular}


The microstructure of samples was observed by utilizing of electron microscopy method and was performed on SEM Hitachi Tabletop 3000 before and after chemical heat-treatment due to comparison of results. The structure after quenching is displayed in Fig. 1. The conditions of heat-treatment process are given in Tab. 1. Gas nitriding process was performed in NITREX appliance for 6 hours in two step process at $530{ }^{\circ} \mathrm{C}$.

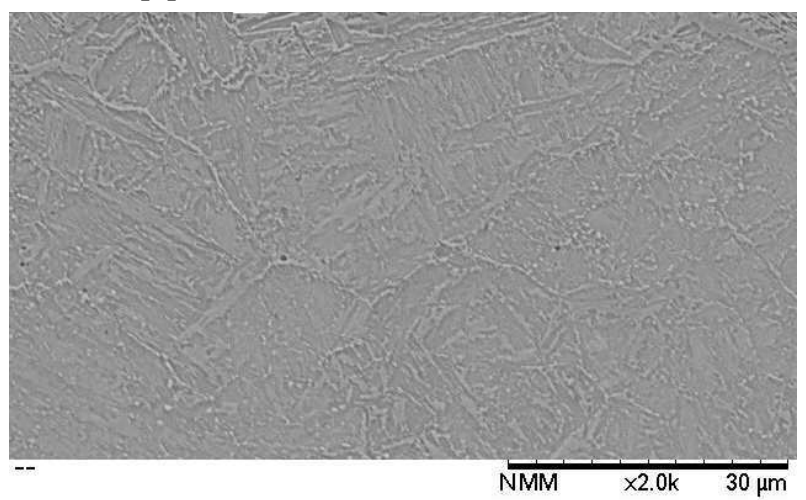

Fig. 1 The chemically etched SE cross-sectional structure of tempered steel, magnification $2000 x$

The microhardness of mentioned samples was evaluated by Vickers microhardness method on the automatic microhardness tester LM 247 AT LECO. Load set at $50 \mathrm{~g}$ and $10 \mathrm{~s}$ dwell time. This method was used for comparison of initial surface microhardness before and after chemical-heat treatment process. The measurements of initial microhardness of heat-treated samples are displayed in Tab. 3 .

Tab. 3 Initial microhardness of core of steel after heattreatment

\begin{tabular}{|c|c|c|c|}
\hline \multirow{2}{*}{ Steel } & \multirow{2}{*}{ Sample } & \multicolumn{2}{|c|}{$\begin{array}{c}\mid c \\
\text { HVitial surface microhardness }\end{array}$} \\
\cline { 3 - 4 } & & Quenched & Tempered \\
\hline C35 & A1 & $499 \pm 31$ & $266 \pm 6$ \\
\hline $34 \mathrm{Cr} 4$ & A2 & $660 \pm 29$ & $328 \pm 11$ \\
\hline $42 \mathrm{CrMo} 4$ & A4 & $645 \pm 24$ & $335 \pm 22$ \\
\hline
\end{tabular}

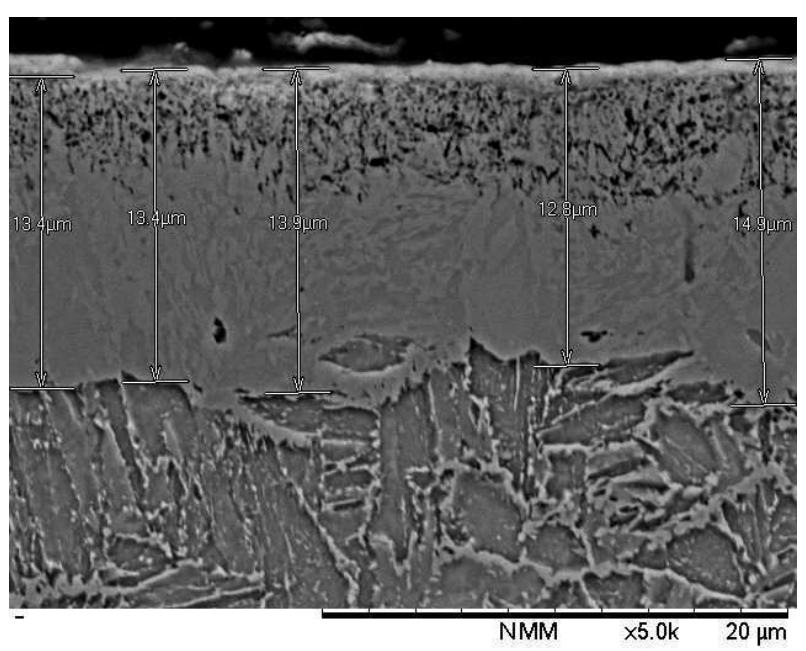

Fig. 2 The chemically etched SE cross-sectional structure of tempered steel A2, the measurement of thickness of compound layer, magnification 5000x
After preparation and nital etching, the electron microscope Hitachi Tabletop 3000 was used for observation of thickness of compound layer (Fig. 2) and especially the documentation of porosity present in the top of compound layer (Fig. 3a-b). The porosity was measured by using SE method and magnification 5000x (Fig. 3), for detailing description the magnification 10000x was ensured (Fig. $6)$.

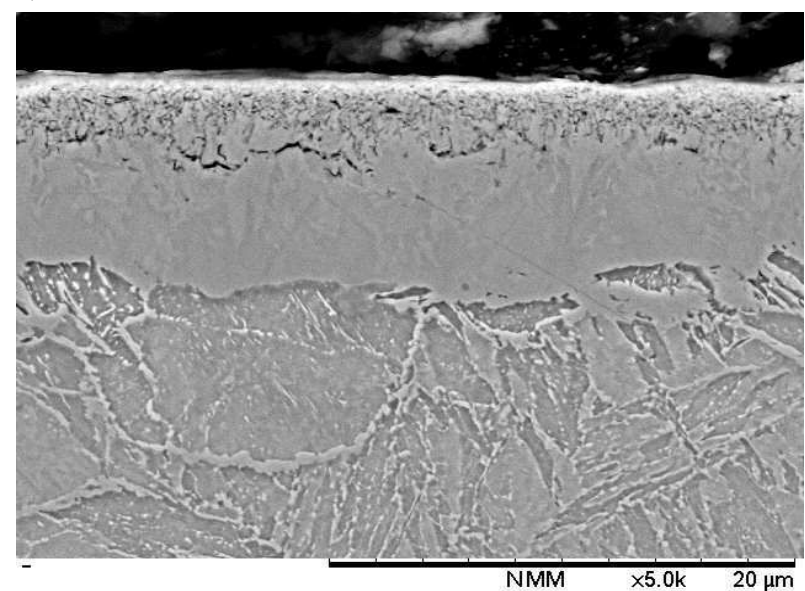

Fig. $3 \boldsymbol{a}$ The chemically etched SE cross-sectional structure of tempered steel A1, compound layer with porosity (top of surface) and diffusion layer below, magnification $5000 x$

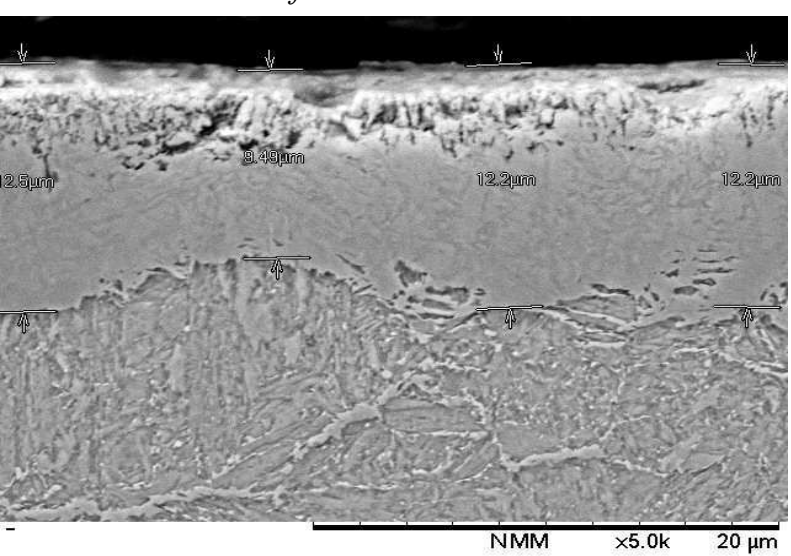

Fig. $3 \boldsymbol{b}$ The chemically etched SE cross-sectional structure of tempered steel A2, compound layer with porosity (top of surface) and diffusion layer below, magnification $5000 x$

\section{Results and discussion}

The microstructure was evaluated by SEM method on microscope Hitachi Tabletop 3000. The structure was obtained by nital etching and was estimated as martensitic microstructure with marks of bainite (see Fig. 1). The chemical composition of steel was evaluated and checked by GDOES method on SA 2000 Leco surface analyzer. The measurements showed the specific chemical composition of selected steels, esp. chromium and molybdenum concentration (Tab. 2). The concentration of molybdenum and chromium influences the fundamental mechanical properties, esp. surface microhardness after chemical heat treatment processes (compare Tab. 2, Fig. 4). The experiments proved the importance of alloying elements concentration as $\mathrm{Cr}$ and $\mathrm{Mo}$, and their influence 
on the depth development. Moreover, the presence of these alloying elements caused the increasing of surface microhardness after chemical-heat treatment (Fig. 4).

It was proved that in case of sample A2, the surface hardness and the depth of diffusion after the chemicalheat treatment was getting up steeper than in case of sample A1. It was caused due to concentration of chromium in case of A2 sample. The concentration of alloying elements $\mathrm{Mn}, \mathrm{Si}$ and interstitial element $\mathrm{C}$ is similar (see Tab. 2). The same trend of microhardness was confirmed in case of sample A4 (Tab. 2). Thanks to the same conditions of gas nitriding process there was possible to evaluate the influence of substitution elements on creation of surface hardness of diffusion layer and depth of nitriding (thickness of diffusion layer). The same progress is expected in case of concentration of V or Mo.

The depth of diffusion layer was increased by higher concentration of $\mathrm{Cr}$ and Mo (Fig. 4). By increasing of $\mathrm{Ni}$ concentration the hardness was decreased. This has to do with abilitz of $\mathrm{Ni}$ to create a nitrides or carbides.

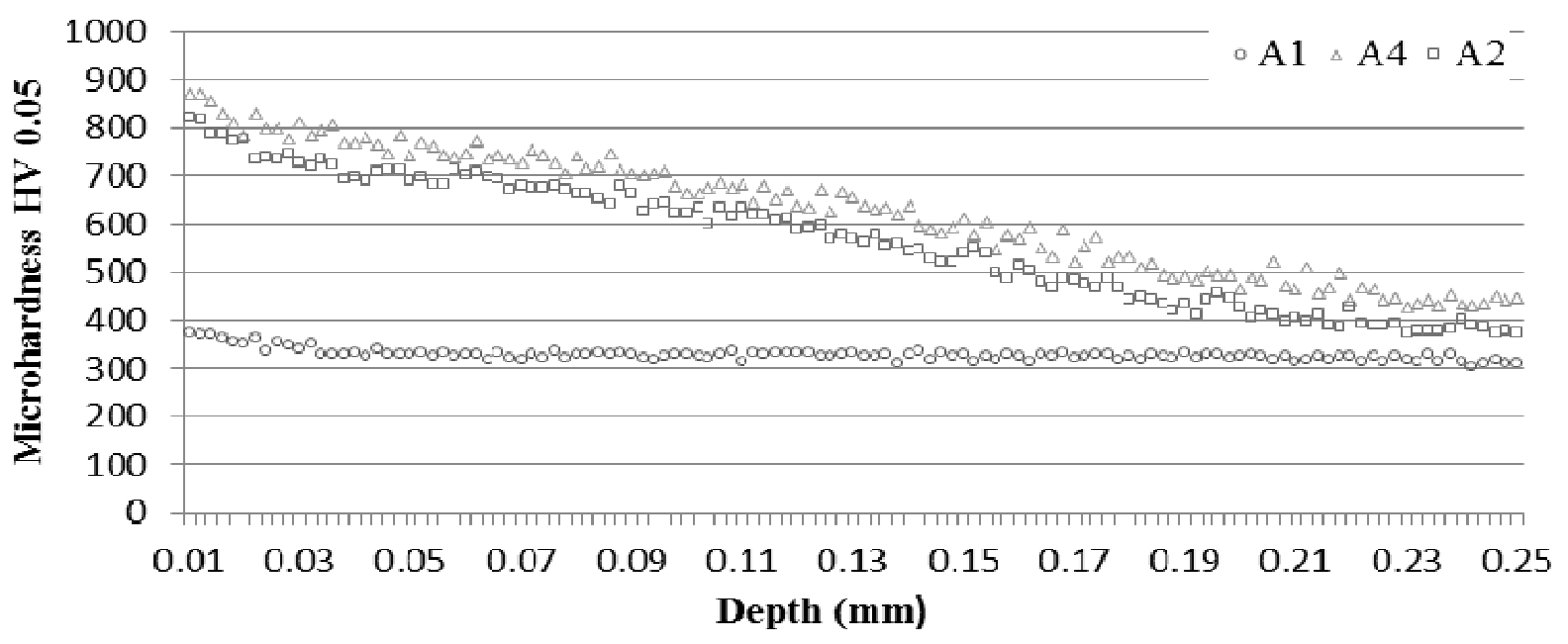

Fig. 4 Influence of alloying elements on surface hardness and depth of nitriding

Moreover, the experiments proved that the increasing of surface microhardness after gas nitriding process is depended on initial microhardness, better said on initial microstructure. This phenomenon was found out thanks to differencies in microstructure after heat treatment process, esp. due to initial surface hardness before nitriding (compare Tab. 3, Fig. 5). The initial microhardness of steel after quenching is usually decreased during process of chemical-heat treatment to tempered values (see Fig. 5). The values of surface microhardness of diffusion layer was evaluated by microhardness method and was measured as a higher in case of quenched samples (Fig. 5).

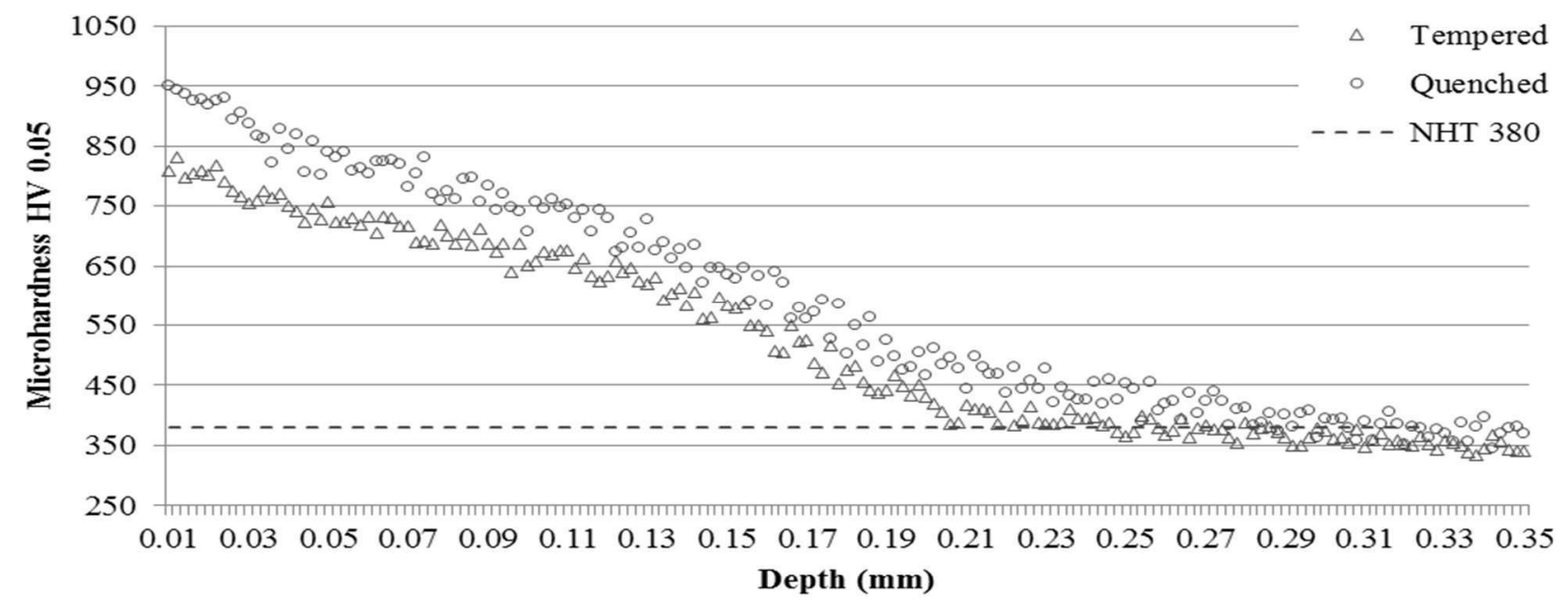

Fig. 5 Microhardness depth profile of A4 sample; gas nitriding process $490^{\circ} \mathrm{C} / 6 \mathrm{~h}$

In fact, the initial microhardness after quenching (Tab. 3) was decreased during the process of chemicalheat treatment due to high temperature close to the $A_{1}$ curve in $\mathrm{Fe}_{-} \mathrm{Fe}_{3} \mathrm{C}$ diagram. Regardless, there was reached higher values of surface microhardness after quenching than after tempering (Fig. 5). The reason is the different type of redistribution of ionts in crystal lattice.

The thickness of compound layer was evaluated by SEM method on electron microscope Hitachi Tabletop
3000 and all results are given in Tab. 4. The lowest thickness of compound layer was measured on A1 sample but the differences of all measured thicknesses are very close. There is possible to consider as the same.

The porosity of compound layer was evaluated by using electron microscopy, too (Fig. 6). The size of pores was measured on electron microscope by magnification 10000x and the results are displayed in Tab. 4. 
Tab. 4 Parametres of nitrided layers

\begin{tabular}{|c|c|c|c|}
\hline Sample & Compound layer thickness $[\mu \mathrm{m}]$ & Depth of diffusion layer [mm] & Porosity [nm] \\
\hline A1 & 9.2 & 0.02 & $370-610$ \\
\hline A2 & 9.7 & 0.20 & $280-890$ \\
\hline A4 & 10.2 & 0.19 & $390-970$ \\
\hline
\end{tabular}

The influence of chemical composition on the sizes of pores was not confirmed. Porosity was present only in the top part of compound layer. The pores are created just only in new established part of compound layer.

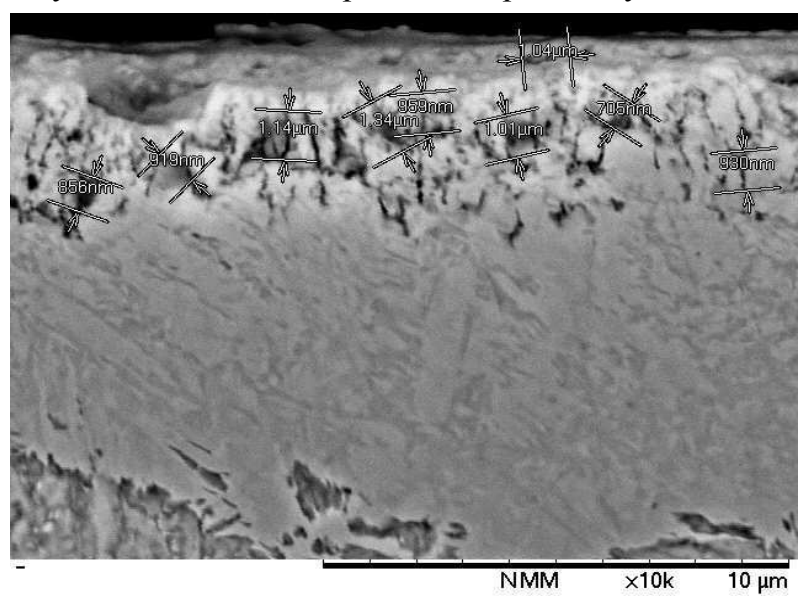

Fig. 6 The chemically etched SE cross-sectional structure of tempered steel A4, documentation of porosity, magnification $10000 x$

This thickness of new established part of compound layer is similar to the dimensional accuracy after gas nitriding technology.

\section{Conclusions}

These evaluated steels with different chemical composition were used for experiments concerning the porosity, microhardness and thickness of compound layer. The basic steel C35 is not entire suitable for application of diffusion processes due to non-effective increasing of mechanical properties (Fig. 4), what it has to do with chemical compositon of steel, esp. the concentration of alloying elements which support the diffusion process inside. The alloying elements Mo and $\mathrm{Cr}$ was causing the increasing of surface microhardness and these elements have remarkable influence on microhardness and depth of diffusion layer. The influence of these elements to the thickness of compound layer was not confirmed. The most occurrence of pores was estimated in the top part of compound layers in all tested steels. The main area of occurrence of pores was established in part of new grown part of compound layer. We are able to reliably define this porosity layer as a new established layer having strict influence on dimensional accuracy. The significant result is a claim that the chemical composition of steel has no influence on occurrence of porosity. The proportions of pores (porosity) are dependent on selected technologies of chemical-heat treatment, it is not more about concentration of alloying elements. In many industry applications there is suitable to remove this part of layer due to creation of defects on the surface, esp. in case of barrels or gears. But in many cases there are new options to use this pores for storage of lubrication [1].

\section{Acknowledgement}

The present research work was supported by the project The Development of Technologies, Design of Firearms, Ammunition, Instrumentation, Engineering of Materials and Military Infrastructure "VÝZBROJ (DZRO K201)" and "Surface technology in applications special techniques SV17-216".

\section{References}

[1] CLARKE, A., JAMALI, HU., SHARIF, KJ., EVAN, HP., FRAZER, R., SHAW, B. (2017). Effects of profile errors on lubrication performance of helical gears. In: Tribology International, Vol. 111, pp $184-191$.

[2] KOSTUREK, R., NAJWER, M., NIESLONY, P., WACHOWSKI, M. (2018). Effect of Heat Treatment on Mechanical Properties of Inconel 625/Steel P355NH Bimetal Clad Plate Manufactured by Explosive Welding. In: Advances in Manufacturing, pp 681-686.

[3] DUBOVSKA, R., MAJERIK, J., BASKA, I., JAMBOR, J (2015). Investigation of cutting temperature during $\mathrm{AlCu} 3 \mathrm{MgMnPb}$ aluminium alloy turning. In: Manufacturing Technology, Vol. 15 , No. 5, pp. $796-801$.

[4] HUTSAYLYUK, V., SNIEZEK, L., CHAUSOV, M., TORZEWSKI, J., PYLYPENKO, A., WACHOWSKI, M. (2016). Cyclic deformation of aluminium alloys after the preliminary combined loading. In: Engineering Failure Analysis, Vol. 69 , pp. $66-67$.

[5] DOBROCKY, D., KUSMIC, D (2015). The Effect of Plasma Nitriding Process on the Change of Dynamic Parameters of Steel DIN 1654/4. In: Manufacturing Technology, Vol. 15, No. 1, pp. $14-20$.

[6] ČSN ISO 14577-1 METALIC MATERIALS - Instrumected indentation test for hardness and materials parameters - Part 1: Test method.

[7] DIN 50190-4:1999, Hardness depth of heat-treated parts - Part 4: Determination of the diffusion hardening depth and the diffusion depth. 